Departamento de Historia Universidad de Santiago de Chile

Revista de Historia Social y de las Mentalidades

Volumen 24, $\mathrm{N}^{\circ} 1,2020$ : 147-168

Issn On Line: 0719-4749

\title{
EL ARCHIVO DEL HOSPITAL PSIQUIÁTRICO EL PERAL: UNA EXPERIENCIA DE INVESTIGACIÓN DESDE LA HISTORIA CULTURAL DE LA PSIQUIATRÍA*
}

\section{THE ARCHIVE OF EL PERAL PSYCHIATRIC HOSPITAL: A RESEARCH EXPERIENCE FROM THE CULTURAL HISTORY OF PSYCHIATRY}

\author{
CLAUDIA ARAYA IBACACHE** \\ Universidad Católica de Chile \\ Santiago, Chile \\ Email: c.arayaibacache@gmail.com \\ Id-ORCID: 0000-0001-7353-0123 \\ NICOLÁS MORALES SÁEZ \\ Universitat Rovira i Virgili \\ Tarragona, España \\ Email: nicolasmoraless@gmail.com \\ Id-ORCID: 0000-0002-0434-2273 \\ CÉSAR LEYTON ROBINSON \\ Universidad de Chile \\ Santiago, Chile \\ Email: cleyton@odontologia.uchile.cl \\ Id-ORCID: 0000-0002-2825-609
}

\begin{abstract}
RESUMEN
Este artículo da cuenta de un trabajo de investigación documental en el Hospital Psiquiátrico El Peral, en Santiago de Chile. Damos a conocer las particularidades de este

\section{ABSTRACT}

This article reports on a documentary research project at the El Peral Psychiatric Hospital in Santiago, Chile. We observe the specific features of this kind of archive, which are
\end{abstract}

* Recibido: 20 de diciembre de 2019. Aprobado: 21 de abril de 2020.

** Artículo científico. Este trabajo es resultado del proyecto Fondecyt Posdoctorado $N^{\circ} 3180429$

“Antecedentes, propuestas y formulación de políticas de salud mental en Chile, 1940-1990", adscrito al Programa de Estudios Médicos Humanísticos de la Universidad Católica de Chile (PEMHUC). 
tipo de archivos, que se relacionan tanto con su contenido como con el acceso a la información. Respecto a lo primero, presentamos los desafíos de trabajar con historias clínicas, fotografías y documentos históricos relativos a las terapias médicas implementadas. Sobre lo segundo, planteamos las dificultades materiales y culturales de acceder a archivos históricamente cerrados para la comunidad, así como las restricciones propias relativas al trabajo con documentos de usuarios con trastornos de salud mental y privados de libertad.

Palabras clave: Archivos psiquiátricos; instituciones de salud; aislamiento; asilos related both to its content and the data access to information. About the former, we present the challenges of working with clinical histories, photographs and historical documents related to the medical therapies implemented. With regard to the second, we present the material and cultural difficulties of accessing historically closed archives for the public, as well as the restrictions inherent in working with documents of users with confined mental health disorders.

Keywords: Psychiatric Archives; Health Institutions; Confinement; Asylums

Cómo citar: Araya, Claudia, Nicolás Morales y César Leyton. (2020). "El archivo del Hospital Psiquiátrico El Peral: Una experiencia de investigación desde la historia cultural de la psiquiatría". Revista Historia Social y de las Mentalidades, 24(1), 147-168. DOI: 10.35588/rhsm.v24i1.4288.

\section{INTRODUCCIÓN}

Los estudios históricos de la psiquiatría en Chile, como en el resto de América Latina, comparten un interés particular por las instituciones psiquiátricas (Escobar y otros; Armijo; Golcman, "Introducción"). Estos estudios tienden a relevar la labor de médicos pioneros como forjadores de la profesión de la mano de avances teóricos y técnicos (Cruz-Coke) e ilustran el desarrollo de la salud pública centrándose en las grandes instituciones hospitalarias. A pesar de esta impronta hagiográfica e institucional, el legado documental de los hospitales en Chile en su gran mayoría no ha sido conservado adecuadamente ni ha recibido ningún tratamiento archivístico. Si bien los archivos hospitalarios son tan solo una entre otras fuentes para la historia de la psiquiatría, su disponibilidad y accesibilidad para la investigación historiográfica son claves para contrastar las prácticas hospitalarias efectivas con respecto a los discursos profesionales y académicos. Más aún, los documentos médicos y administrativos permiten explorar una serie de procesos relevantes para un análisis histórico, social y cultural de la psiquiatría, que den cuenta de la perspectiva tanto de profesionales como de usuarios.

Los archivos de las instituciones psiquiátricas han presentado una serie de dificultades para los investigadores. En Canadá, Klein, Perrault y Thifault a partir del ejemplo del antiguo asilo de Saint-Jean-de-Dieu de 
Montreal, ahora transformado en el Institut Universitaire en Santé Mentale de Montréal (IUSMM), se interrogan por las dificultades de acceso a las fichas clínicas de más de 192 mil ex-pacientes, y de los medios disponibles para su conservación. A las consideraciones económicas y del espacio requerido para la conservación de un volumen tan grande de documentación, los investigadores añaden otras cuestiones tales como ¿quién tiene derecho a consultarlas?, ¿cuánto tiempo han de ser conservadas?, y ¿cómo se adapta la legislación a la digitalización de cierta documentación? Según las legislaciones nacionales y las normativas locales, los archivos hospitalarios plantean diversos desafíos respecto de su conservación, transferencia y políticas de acceso a la información. En Chile, la carencia de una legislación específica sobre archivos y la disposición de una serie de indicaciones en diferentes normativas de la administración pública, configuran un escenario aún más complejo para los archivos hospitalarios. En términos de los actos administrativos, numerosa documentación puede considerarse obsoleta y ser eliminada, sin pasar por un proceso de valoración que indique su necesidad de ser dispuesta al resguardo de un archivo histórico. Lo propio acontece con las fichas clínicas, como abordaremos más adelante.

Los archivos psiquiátricos permiten acceder a una diversidad de actores $\mathrm{y}$, sobre todo, dan cuenta de las relaciones entre locura, cultura y sociedad. En este sentido, los archivos no son entidades dadas por descubrir, sino construcciones de memorias por realizar (Cook). Siguiendo esta premisa, en este artículo, a partir de un trabajo de investigación documental e historiográfico que hemos iniciado en 2017, nos centramos en problematizar la relación entre archivos e historia cultural de la psiquiatría a partir del caso del Hospital Psiquiátrico El Peral (en adelante HPEP) (Huertas, Historia cultural). En los siguientes apartados, se exponen brevemente los antecedentes del caso de estudio, el trabajo de investigación documental realizado, los desafíos analíticos que emergen de este proceso y, finalmente, una discusión desde la historiografía y la antropología social en la cual se señalan algunos avances de investigación que permiten vislumbrar las potencialidades de este archivo hospitalario. 


\section{EL HOSPITAL PSIQUIÁTRICO EL PERAL}

Los hospitales psiquiátricos en Chile corresponden actualmente a cuatro instituciones públicas, ubicadas en el centro del país. ${ }^{1}$ Entre ellas, el HPEP ha destacado por su posición periférica respecto al Instituto Psiquiátrico Dr. José Horwitz Barak. Este último, heredero de un pasado institucional que remite a la antigua Casa de Orates, la primera institución asilar del país, ha sido también la institución más estudiada desde la historia de la psiquiatría realizada por médicos (Escobar et al.) e historiadores (Camus; Leyton; Correa). A pesar de su tradición, el Instituto Psiquiátrico no escapa a la realidad de todas las instituciones psiquiátricas o de asistencia mental chilenas; esto es, la ausencia de archivos históricos. De acuerdo a Heredia, un archivo histórico es "aquel cuyo contenido documental, tras la valoración hecha en los Archivos anteriores, es de conservación permanente, constituyendo una parte del Patrimonio documental histórico. Su finalidad prioritaria es el servicio a la investigación y a la cultura" (Heredia 64). La autora, al expresar "Archivos anteriores", hace referencia a una red en la cual el archivo histórico es el depositario de una gestión documental previa, expresada en el trabajo de archivos de oficina, centrales e intermedios. A lo que apuntamos es a la distinción entre documentos y Archivo: "No hay Archivo sin documentos, aunque sí documentos sin Archivo" (Heredia 43). En ese sentido, señalamos que, si bien en la biblioteca del Instituto Psiquiátrico se conservan los libros impresos de Memorias de la Casa de Orates y una colección fotográfica de 1924 y 1925, no existe respecto a esos documentos una "valoración" de su contenido y tampoco una "conservación permanente" que lo constituya en un "patrimonio documental histórico", donde "su finalidad prioritaria es el servicio a la investigación y a la cultura".

El Peral tiene su origen como un antiguo asilo-colonia de "puertas abiertas" creado en 1928 bajo el nombre de Open Door, como dependencia de la Junta Central de Beneficencia (Gómez y Villanueva). Su origen se sitúa en la modernización sanitaria y urbana de la dictadura militar del general Carlos

1 Cada hospital psiquiátrico depende en la actualidad de un Servicio de Salud distinto: el Hospital Psiquiátrico El Peral está ubicado en Puente Alto y depende del Servicio de Salud Metropolitano Sur; el Instituto Psiquiátrico Dr. José Horwitz Barak está ubicado en Independencia y depende del Servicio de Salud Metropolitano Norte; el Hospital Psiquiátrico Dr. Philippe Pinel está ubicado en Putaendo y depende del Servicio de Salud Aconcagua; y el Hospital Psiquiátrico del Salvador está ubicado en Valparaíso y depende del Servicio de Salud Valparaíso-San Antonio. Otras instituciones asilares ya extintas fueron el Manicomio de Concepción y el Asilo Avello, ambos situados en Concepción. 
Ibáñez del Campo (1927-1931). El hospital fue fundamental en la inclusión sanitaria de la población rural migratoria, ya que fue emplazado en una antigua hacienda agraria, ideal para la transición de los pacientes no exitosos en este proceso de modernidad. Esta "colonia" fue un pequeño laboratorio terapéutico de inserción de los contingentes campesinos pobres y de alienados de provincia, que ingresaban por el sureste de la ciudad de Santiago, ruta histórica de la migración meridional del país.

El asilo fue situado en las afueras de Santiago, en el fundo El Peral, próximo a la línea del ferrocarril que unía Santiago con Puente Alto. En diferentes momentos de su historia numerosos contingentes de "pacientes crónicos" fueron trasladados desde otras instituciones asilares (por ejemplo, desde el Hospicio de Santiago, a principios de los setenta). En 1945 consigue su autonomía bajo la dirección del Dr. Carlos Larson y se renombra como Hospital Colonia El Peral. Luego, con la creación del Servicio Nacional de Salud en 1952 pasa a formar parte de la V Zona de Salud (Zanghellini).

El programa médico-social que vivió su apogeo entre 1920 y 1940 se enmarcaba dentro del paradigma de la higiene mental. El Instituto de Reeducación Mental (IRM) que funcionó en el HPEP fue creado en 1940 para el tratamiento psiquiátrico de alcohólicos y toxicómanos como parte del proyecto de educación en higiene mental. Toxicomanías, alcoholismo y morfinomanía se atendieron en la institución. A medida que el hospital decaía, producto de la presión de la marginalidad urbana que crecía constantemente y la falta de políticas públicas en salud mental, derivó en un nuevo espacio manicomial, donde el encierro y la concentración de pacientes crónicos se institucionalizaron. El hospital no solamente se convirtió en un asilo clásico, sino que además fue un espacio de castigo para médicos y funcionarios que no cumplían las normas administrativas. La burocracia sanitaria de mediados de siglo XX, llamaba a El Peral una "colonia penal" por ser un lugar de castigo para profesionales y funcionarios de la beneficencia pública, incluyendo a médicos y psiquiatras con problemas de adicciones (Zanghellini).

Durante la dirección de German Zanghellini (1977-1981) el HPEP comienza una experiencia de rehabilitación en el Pabellón 10 a través de un programa de Economía de Fichas de corte conductista, con la asesoría del Departamento de Psiquiatría y Salud Mental de la Facultad de Medicina Sur de la Universidad de Chile. La evaluación inicial de Juan Marconi en 1976 es devastadora, pues describe el asilo como un "establo humano" con altas tasas de mortalidad y morbilidad, desnutrición crónica, condiciones inhumanas de los pabellones y escasez de personal auxiliar y médico (Marconi). Zanghellini encarga en 1978 a un fotógrafo profesional una serie documental que plasma 
la realidad de abandono asilar en un álbum con 49 fotografías tituladas en inglés, el cual lleva personalmente en un viaje a Londres donde consigue apoyo financiero para la creación de un hogar protegido dependiente del hospital. A este lugar ingresan al menos 22 pacientes procedentes de la institución hasta 1980 (Martínez).

Las transformaciones en la psiquiatría asilar han sido parciales y con fuerte resistencia tanto por parte del gremio psiquiátrico como de los sindicatos de trabajadores de la salud. En un documento de 1997 los directores de los cuatro hospitales psiquiátricos defendían el rol de sus instituciones aseverando que cubrían el 80 por ciento de las camas psiquiátricas (Boisier y Fariña). En 1990 los países miembros de la Organización Panamericana de la Salud firman la Declaración de Caracas donde se los insta a concretar la reestructuración de la asistencia psiquiátrica. Siete años después, en Chile, el único hospital psiquiátrico que intentó reconvertirse bajo los criterios reformistas fue el HPEP. La oposición interna al proyecto no impidió que se cerraran sectores de larga estadía y que cientos de personas egresaran a hogares protegidos. Un grupo de ellos había participado de un taller de radio que se denominó Radio Estación del Paraíso a partir de 1998. Parte de esta experiencia aparece reflejada en el documental de Francisco Schultz La furia de los caballos sin patas, donde se recogen las voces en primera persona que muestran una experiencia transformadora. Con el cierre del Pabellón 7, varios de ellos egresaron a hogares protegidos y así también la radio fue "egresada" en 2002 a un espacio dentro de las dependencias del Servicio de Salud Metropolitano Sur, próxima al hospital general Barros Luco Trudeau, donde los ex-internos continuarán siendo atendidos en el Servicio de Psiquiatría ambulatoria.

\section{EXPLORANDO EL ARCHIVO DEL HOSPITAL PSIQUIÁTRICO}

En 2017 iniciamos un plan de trabajo que tuvo como objetivo principal describir, valorar y difundir la documentación que se encontraba en el HPEP. Como equipo de investigadores nos propusimos además desarrollar líneas de investigación vinculadas con la historia social y cultural de la psiquiatría chilena y con las políticas de asistencia mental. De este modo, hemos comenzado a preparar publicaciones, la primera de ellas sobre una de las terapias implementadas en el Hospital en la década de 1970.

Para la elaboración del plan de trabajo realizamos un inventario de la documentación disponible, así como entrevistas enfocadas a la pesquisa y 
levantamiento de documentación que no se encontraba organizada. El plan de trabajo comenzó a implementarse en 2018 con la limpieza y aplicación de medidas básicas de conservación de los documentos. Se compraron papeles, carpetas y cajas de cartón libres de ácido con estándares internacionales de conservación. En esta primera parte se rescataron y conservaron aproximadamente 200 fotografías, en distintos formatos y con diferentes técnicas. Se digitalizaron además imágenes de libros para que quedaran disponibles para la colección fotográfica. Se digitalizó también un diaporama de 80 diapositivas donde se narra la experiencia terapéutica de la comuna protegida en los ochenta, que tuvo como finalidad disponer a los pacientes y a los funcionarios orgánicamente como si vivieran en una comuna cualquiera del país.

Se dio un tratamiento similar a los otros tipos de documentos encontrados, como carpetas con información de trabajadores y documentos oficiales de la Dirección del hospital. Otro de los productos de nuestro trabajo es el rescate de más de 300 historias clínicas, las que fueron digitalizadas y actualmente se encuentran en proceso de organización. Algunas historias clínicas contenían distintos documentos, como dibujos y cartas, por ejemplo, que también recibirán un tratamiento adecuado.

Durante el año 2019 se diseñó una ficha de catalogación que permite clasificar, describir y ubicar cada uno de los documentos. A continuación, comenzamos el proceso de organización del Archivo, creando el Fondo Hospital Psiquiátrico El Peral, los sub-fondos constituidos y las series respectivas. A la fecha hemos elaborado un número aproximado de 500 fichas descriptivas. Con la asesoría de una archivera estamos creando una base de datos del Archivo HPEP. Una vez concluida la base de datos, podremos elaborar la Guía de Fondo. Durante el año 2020 esperamos la habilitación de un espacio físico y virtual que resguarde y permita la difusión del archivo.

El marco temporal de la documentación se extiende entre fines de la década de 1950 y el año 2000. Su contenido es diverso. Hemos mencionado que el Archivo está compuesto de fotografías; historias clínicas; y registros del personal de la Institución, donde se consignan las licencias, los currículos, recomendaciones laborales y datos familiares.

Hay además una serie de documentación administrativa de la Dirección, datada entre 1987 y 2006. Esta incluye documentación formal como resoluciones y documentos ordinarios; documentos fundacionales; reseñas históricas de la profesora de la Escuela Diferencial del Hospital, Margarita Martínez Salazar del año 1977; una breve relación del sistema de comuna protegida creado bajo dirección del Dr. Cristian Wulff; y la crónica, "El Peral: una visión sistemática", de la Dra. Gloria Gramegna. 
Respecto al registro de imágenes, el Archivo contiene un álbum de 49 fotos, entre los años 1976 y 1978, con índice, encargadas por Germán Zanguellini, ya referido en el apartado anterior. Además, hay aproximadamente 20 fotos de formato grande, realizadas por el fotógrafo Álvaro Mardones en 1978. Se incluye también el diaporama mencionado antes y un cassette explicativo realizado por los funcionarios Alejandro Riveros Lepe y Ma. Angélica Contreras.

Con el fin de mantener una mirada que desborde el estricto marco archivístico respecto del fondo HPEP, hemos complementado este corpus con el desarrollo de una biblioteca auxiliar, que incluye diversas publicaciones sobre el HPEP, artículos de prensa, documentales, investigaciones académicas, entre otras. Además, con interés historiográfico, hemos realizado una serie de entrevistas a médicos y funcionarios del Hospital que nos han permitido esbozar líneas de investigación que esperamos desarrollar en el corto plazo.

\section{PROBLEMATIZANDO EL ACCESO Y EL TRATAMIENTO DE LOS DOCUMENTOS}

Las características del Archivo del HPEP nos plantean nuevos desafíos, no solo relativos a la diversidad de su contenido (psiquiátrico, psicológico, institucional, entre otros), sino también a la ausencia de referentes nacionales en la materia. En este sentido, podemos vislumbrar que, una vez concluida esta investigación aplicada, el Archivo del Hospital Psiquiátrico El Peral se constituirá en el primer archivo histórico médico-psiquiátrico en Chile.

Hemos agrupado en dos aspectos principales las problemáticas concretas que ofrece un archivo hospitalario psiquiátrico. En primer lugar, las relacionadas con las políticas de acceso a la información de usuarios con internamiento psiquiátrico. En segundo lugar, las problemáticas vinculadas con la riqueza y complejidad del tipo de documentación que alberga un archivo de esta naturaleza.

\subsection{Políticas de Acceso a la información}

La carencia de políticas públicas de archivo en el Sector Salud ha tenido una serie de impactos negativos. En Brasil, Santos describía el panorama de los archivos de hospitales federales del Estado de Rio de Janeiro a fines de los noventa, señalando como rasgos principales: "falta de organización; infraestructura muy deficiente de conservación; uso indiscriminado de microfilm; dificultades de acceso, entre otros" (Santos y Pinto 29). Tras este diagnóstico, en el año 2002 se crea la Câmara Setorial de Arquivos de 
Instituições de Saúde, como parte del Consejo Nacional de Archivos. El caso de El Peral refleja un panorama chileno similar para el Brasil de los noventa. Numerosos cuerpos documentales en diferentes reparticiones del hospital, algunos sin ningún orden ni resguardo tales como historias clínicas depositadas en un pabellón psiquiátrico clausurado.

Diversas investigaciones dan cuenta de las dificultades para acceder a información médica e institucional de hospitales psiquiátricos y otros dispositivos sanitarios relacionados. En Canadá, LeBel ha comunicado una experiencia frustrada de acceso a archivos de atención psiquiátrica de población francófona en Ontario, vinculada a procesos de transferencia documental entre diversas instituciones. En Francia, Neuschwander ha descrito cómo los procesos de eliminación y diversos "accidentes históricos" (tales como la guerra) han dificultado la construcción de una serie histórica larga de la asistencia y la previsión social a través de la búsqueda de documentación en los archivos departamentales. Estos ejemplos dan cuenta de que, a pesar de la existencia de archivos médicos históricos organizados, muchas veces el proceso de acceso a la información que contienen es bastante complejo. Numerosos "accidentes históricos" han afectado la conservación de documentos en el HPEP: incendios, terremotos y otros sucesos han mermado la preservación de un archivo histórico. En una comunicación personal, la secretaria de la Dirección nos comentaba que no tenían indicación de transferir documentación administrativa al Archivo Nacional de la Administración, y que podían eliminar la documentación que consideraran no útil. Ante este escenario, concordamos con Alexandre Klein, que es también tarea del historiador -y de la historiadora-contribuir a través de diversas gestiones para la preservación de fondos documentales en riesgo.

Al registrar el acervo documental de El Peral, el trabajo de valoración archivística permite priorizar algunas "voces sumergidas" en la institución, tales como la perspectiva de los usuarios (Perrault y Thifault). En el siguiente apartado, profundizaremos en esta cuestión, pero antes queremos plantear algunas consideraciones sobre las dificultades de acceso esgrimidas desde la protección de datos personales y la confidencialidad de los actos médicos ${ }^{2}$.

Un primer desafío es el recelo profesional que bajo el argumento del secreto médico impide consultar estos registros. La carencia de políticas de acceso a la información vuelve este proceso poco transparente y a menudo

2 La regulación de la investigación científica con seres humanos, incluye el resguardo de la información personal. En muchos países anglosajones existe una restricción de acceso de cien años para los registros médicos (Wright y Saucier). 
tiene un carácter discrecional. La Ley 20.584 en su artículo 13 indica que el prestador de salud resguardará la ficha clínica durante un período de al menos 15 años, siendo competencia del Ministerio de Salud indicar los procedimientos de administración, protección y eliminación. Pero ni en la ley referida ni en el reglamento asociado (No 41, 2012) existe mención a actividades de investigación sobre estos registros que son considerados "sensibles".

Un segundo desafío abierto es la paradoja entre el deber de resguardar la privacidad individual y, al mismo tiempo, querer dar "voz" a sujetos marginalizados bajo el marco de la historia social (Wright y Saucier). Muchas veces, prima la anonimización de los datos como solución parcial, transformando las historias personales en "casos". Desde enfoques más recientes ligados a la historia pública y la memoria, el nombrar es un tema sensible, en el sentido que restituye la visibilidad y la memoria de colectivos subalternizados.

Las implicancias éticas del acceso a la información en el marco de una investigación historiográfica o antropológica sobre archivos hospitalarios se ubican más allá de los requerimientos formales de la aprobación de un Comité de Ética de la Investigación que velará por los aspectos antes señalados sobre la confidencialidad de la información personal y el secreto profesional. Se trata de considerar el análisis ético como elemento constitutivo de la investigación, que debe valorar en cada caso, tanto los debates del pasado respecto a la historia del campo de conocimiento, como los desafíos del presente, en particular frente a colectivos subalternizados que demandan una ética de justicia (Gallois).

\subsection{Tipos documentales}

Dentro de la diversidad de tipos documentales, en este artículo nos centramos en las historias clínicas y las fotografías como fuentes que permiten profundizar en una historia social y cultural de la psiquiatría.

\subsubsection{Historias clínicas}

Las historias clínicas representan una valiosa fuente para la historia de la psiquiatría. En un análisis metodológico, Rafael Huertas ("Las historias clínicas") sostiene que la información disponible en las historias clínicas, además de permitir establecer modelos patográficos, facilita otros tipos de análisis que entran de lleno en el campo de la historia social, al favorecer estudios de demografía y epidemiología histórica, y de la historia de las instituciones o de la 
historia conceptual, al evidenciar una práctica clínica que no siempre coincidió con los conocimientos o los paradigmas imperantes. Asimismo, el clásico tratado de Pedro Laín Entralgo - La historia clínica- constituye, sin duda, un punto de referencia inevitable respecto a la importancia de las historias clínicas para la investigación de la historia médica al sustentar la relación directa entre el relato patográfico y las ideas médicas imperantes.

Aunque en Chile existe un desarrollo importante de la historiografía social, son muy pocos los estudios que pudiéramos citar que hayan recurrido directamente a este tipo de fuente. Solo encontramos un trabajo de tesis de grado que a partir de fichas clínicas del Hospital Psiquiátrico de Santiago aborda las llamadas terapias biológicas (Molettieri). Otros tres estudios incluyen algunos datos estadísticos obtenidos de la revisión de historias clínicas: de Paula Bell (1995), Locura y familia: sesenta casos del manicomio nacional entre 19251950; de Claudia Carrillo y Pamela Figueroa (1995), La locura en el Chile decimonónico; y de Araya (2010), Mujeres, médicos y enfermedad mental en la segunda mitad del siglo XIX. En este último caso no se utilizan historias clínicas bajo el formato de ficha médica sino más bien casos clínicos que se analizaban en las clínicas, realizadas por los médicos ante los estudiantes, y que eran luego publicadas en la Revista Médica de Chile.

Para Juan Luis Linares, la historia clínica psiquiátrica tiene una doble condición de espejo: de los mecanismos marginadores conducentes al internamiento, $\mathrm{y}$ de expresión de la ideología psiquiátrica justificadora del mismo. El análisis de Linares se sostiene teóricamente en los clásicos trabajos de Erving Goffman sobre manicomios. De acuerdo a Goffman, mediante la fundamentación del tratamiento en el diagnóstico del paciente, y en la interpretación psiquiátrica de su pasado, los hospitales institucionalizan burocráticamente esta competencia, siendo la historia clínica una importante expresión de ese mandato. En una línea similar, de inspiración foucaultiana, Thomas Anz sostiene que a partir del s. XVIII las estrategias para instituir normas y valores sociales comienzan a relacionarse con discusiones vinculadas con el saber médico y que la legitimación de dichas normas y valores se realiza a través de los argumentos médicos oficializados mediante documentos de registro como las historias clínicas.

En México, Andrés Ríos sostiene que escritos de pacientes encontrados en las historias clínicas del Manicomio General La Castañeda, evidencian que las voces de los locos fueron desdeñadas por las autoridades médicas al ser tomadas como consecuencias propias de la locura. Estos pacientes habían sido trasladados al Manicomio en 1910 cuando los hospitales para hombres y mujeres dementes habían sido clausurados. Según Ríos, los pacientes fueron 
observados y clasificados minuciosamente por los psiquiatras, con el objeto de elaborar un diagnóstico que justificase el secuestro de los pacientes. En la misma institución, Rivera Garza profundiza en las narrativas de internos e internas a partir de las historias clínicas entre 1910 y 1930, dando cuenta de una multiplicidad de voces que se expresan en las narrativas de padecimiento que dan cuenta de una estructura institucional atravesada por opresiones de género y clase.

De las historias clínicas es posible inferir además información relevante sobre la trayectoria previa al ingreso psiquiátrico. Una cadena antecesora de instituciones médico-judiciales que gestionan al paciente (o pre-paciente en términos goffmanianos) y lo acompañan antes de llegar a la institución psiquiátrica: tribunales, instituciones correccionales y de beneficencia (cárceles, asilos de pobres y reformatorios de menores). En el ingreso se consigna además información proporcionada por los familiares, trayectorias de abandonos, hospitalizaciones previas en otras instituciones médicas. Se configura, de este modo, una biografía clínica y social, construida por diferentes agentes, que junto a los datos sociodemográficos incluidos, permiten construir un perfil cultural y geográfico de la población asilada (Huertas, Historia cultural).

Los diagnósticos y el control de los tratamientos han sido un eje central para intentar comprender estas vidas institucionalizadas. Estas vidas han estado no solamente signadas bajo un rótulo médico, sino también forman parte de una historia social fragmentaria (Rivera Garza) que había sido sentenciada con la declarada cronicidad del paciente. En este sentido, los múltiples diagnósticos evocados por los especialistas arrojan luces sobre la vida de los internos que, entre otros aspectos, reflejan la miseria social y la explotación económica sobre una población mayor. Venancio y Potengy han ilustrado las múltiples lecturas que una institución asilar puede brindar desde un enfoque histórico y antropológico, respecto al espacio social de la locura en la ciudad de Río de Janeiro. Las relaciones entre el hospital, la comunidad vecinal y la ciudad nos permiten observar cómo ciertos imaginarios de la locura -sobre todo aquellos estigmatizadores y segregadores-permanecen en el tiempo.

Campesinos, policías, jornaleros, obreros, cesantes, dueñas de casa, comparten este espacio "terapéutico" de encierro. Los establecimientos laborales y estatales solicitan su tratamiento en la institución. Las fichas clínicas contienen los alegatos de los parientes, que demuestran su fracaso por asistirles. Esta perspectiva es fundamental, ya que muchas veces, la construcción del diagnóstico es construida por el psiquiatra con la ayuda de las narraciones de los propios familiares. En los mismos legajos comparten existencia dibujos, pruebas 
de inteligencia, exámenes de tuberculosis y alcoholismo, entre otros. Asimismo, $\operatorname{cartas}^{3}$ y otros escritos, aunque no tan frecuentes, configuran un universo letrado de pugnas muchas veces soterradas en el nombre de la locura.

\subsubsection{Fotografias}

Desde sus orígenes la fotografía ha estado vinculada, más allá de sus aspectos artísticos y técnicos, con el poder y el conocimiento al servicio de los sistemas de control estatal. En el siglo XIX los registros fotográficos pasaron a formar parte de las prácticas discursivas de una serie de instituciones disciplinantes como la policía, los hospitales y los manicomios. El carácter de estas instituciones promovió una institucionalización de la fotografía "mediante el modelo de archivo", de acuerdo al cual la imagen fotográfica se integra a un proceso administrativo, estadístico y burocrático, transformándose en una nueva forma de conocimiento y poder, favoreciendo el control institucional del individuo (Grigoriadou 79).

La vinculación entre iconografía y alienismo también fue temprana. Antes de la fotografía se recurrió a grabados y dibujos. En 1856, cuando la ciudad de Santiago se encontraba alterada por los ataques convulsivos de una mujer joven en un convento de la ciudad, la Iglesia Católica solicitó al pintor Alejandro Cicarelli dibujar los ataques como apoyo a los debates que médicos y clérigos sostenían acerca de si aquellos eran producto de la posesión demoniaca o de alguna patología (Roa). De algunos años antes, en 1851, provienen las primeras fotografías de enfermos mentales. Fueron realizadas por Hugh W. Diamond en el Asilo para locos del Condado de Surrey. A partir de ahí, esta práctica se fue generalizando tanto en la clínica psiquiátrica como en el ámbito médico-legal.

Concretamente en la clínica, en el último tercio del siglo XIX, la fotografía tuvo un papel clave en la elaboración de la histeria como categoría diagnóstica (Huertas, "Imágenes"). El manicomio francés para mujeres La Salpêtrière incorporó un servicio de fotografía, dirigido por el médico y fotógrafo Albert Londe. Su trabajo dio lugar a una gran colección de fotografías de los ataques histéricos que fueron publicadas en la revista Iconographie photographique de la Salpêtrière bajo la dirección del director del asilo, Jean-Martin Charcot, entre 1876 y 1880, y que se han convertido en ícono de la constitución de un saberpoder médico a través de la clínica (Didi-Huberman). a inicios del s. XX. Y también, una compilación de Olga Villasante y otros, de cartas de la Casa de Dementes de Santa Isabel en Leganés, a mediados del siglo XX. 
Si en el siglo XIX la fotografía se convirtió en instrumento de clasificación y disciplinamiento, en el XX fue vehículo de denuncia, testimonio, memoria histórica y expresión artística, sintonizando con los procesos de desinstitucionalización asilar que experimentaba el mundo occidental, especialmente Italia (Martínez y Serrulla). Franco Basaglia, uno de los principales críticos del manicomio, convocó a varios fotógrafos para mostrar los efectos de la institucionalización en los internos. Como resultado, en 1968 publicó el libro Morire di clase, donde se recogen fotografías tomadas en hospitales de Florencia, Gorizia y Parma. En la misma línea, en 1996, Gilberto Di Petta publica un libro de fotografía manicomial donde se registra el "antes y el ahora" de 13 mujeres al momento de su ingreso y luego de varias décadas de institucionalización.

Estos registros fotográficos construyen un pasado determinado, donde no ha llegado la ciencia médica o psicológica, para contrastarlo con un "después" constituido a partir de ellas. Si bien aquí el "antes y el después" se usa también como legitimación de un saber-poder médico, no es menos cierto que se hace desde una posición mucho más democrática y horizontal que la visión de control institucional decimonónico. En un plano similar también la fotografía ha permitido visualizar la materialidad del espacio, la organización de los pabellones en los manicomios, evidenciando concepciones determinadas respecto a la segregación y al orden científico (Scull).

En el caso concreto del HPEP, la colección fotográfica es uno de los patrimonios principales. En la descripción del archivo ya nos referimos en general a las fotografías que alberga la institución. En términos más específicos, se conserva un registro medianamente extenso de la situación de los pacientes del Hospital en la década de 1970. El objetivo de la serie es denunciar las pésimas condiciones humanas y materiales en las que se encontraban los internos. Otra serie muestra imágenes en color, durante y después de la aplicación de algunas terapias psicológicas. En ambas series es posible advertir la construcción médica del "antes y el después" de la intervención médica institucional. En estas fotografías aún se conserva, por parte de médicos y psicólogos, el espíritu de cambio social que habían instalado los programas de psiquiatría comunitaria del área sur de Santiago antes del Golpe Militar de 1973. Es posible comparar estas series con otro pequeño cuerpo fotográfico de la década de 1980 donde se muestra a los pacientes en las Olimpiadas de hospitales psiquiátricos que se llevaron a cabo en esos años. A diferencia de las anteriores, esta mantiene una estética y un trasfondo ideológico característicos de la Dictadura Militar. 
En estos documentos visuales quedan plasmados los avances terapéuticos, pero son también un registro inclemente del dolor psíquico producido por el padecimiento y por la institucionalización de los pacientes. Incluso muestran el padecer psíquico de la infancia abandonada y encarcelada. Nos encontramos ante registros donde la locura está presente; no aquella disciplinada del orden estético del Estado y del poder médico, si no esta otra, la de las personas atrapadas en un tiempo y en un espacio muertos. Las posibilidades que nos dan las fotografías que se conservan son mucho más amplias que las que se refieren a los objetivos por los cuales fueron realizadas. Podemos visualizar a través de ellas prácticas cotidianas de los pacientes, niños y adultos; características espaciales y arquitectónicas de un sistema asilar como este, definido como de puertas abiertas; el trabajo agrícola realizado y una serie de otros aspectos materiales importantes para construir la historia de la psiquiatría, la locura y la asistencia mental en Chile.

Los desafíos concretos que nos presentaron las fotografías fueron amplios. Para realizar la ficha de catalogación lo más completa posible, recurrimos a entrevistas a personas que habían participado de alguna manera en su ejecución o que habían trabajado en la institución en esos períodos. También realizamos investigaciones históricas que nos permitieran identificar a los autores y situar las fotografías temporal y espacialmente. Algunas de las fotografías habían sido utilizadas en publicaciones específicas sobre el tema, pero con fines únicamente ilustrativos; de todos modos, fueron de utilidad. Paralelamente realizamos un levantamiento de material fotográfico que no estaba constituido como documento del Archivo, pero que será de interés para futuras investigaciones.

\section{ARCHIVOS PARA OTRA SALUD MENTAL}

Los archivos sobre padecimientos mentales han sido un campo de estudio historiográfico desde la década de 1950. En una de las investigaciones pioneras del historiador de la medicina Pedro Laín Entralgo se reconstruyen, a partir de fichas clínicas, diagnósticos, patografías y tratamientos del pasado médico. Estos estudios han sido renovados, por lo menos, desde los últimos diez años, en escuelas historiográficas latinoamericanas y españolas que han profundizado específicamente en los archivos de la psiquiatría. Países como México y España han sido los pioneros en este tipo de investigaciones, generando estudios en los establecimientos principales de sus respectivos países: el Manicomio de La Castañeda de la capital azteca, fundada en la 
modernización del porfiriato mexicano (Rivera Garza; Ríos et al.); y los trabajos en España sobre el manicomio de Leganés en Madrid, conducidos en forma mixta por psiquiatras e historiadores (Villasante et al.). A esto se han sumado, más recientemente, los estudios sobre los archivos psiquiátricos de Buenos Aires (Golcman, El trabajo clínico), a través de numerosos proyectos y valiosas publicaciones sobre las experiencias psiquiátricas de estos archivos asilares.

La constitución del archivo del HPEP aportará al desarrollo de una serie de líneas de investigación que se habían quedado atrás, permaneciendo al margen del actual debate historiográfico latinoamericano. Entre ellas destacamos líneas de investigación sobre las terapias ocupacionales, la infancia "anormal", la historia desde "abajo" de pacientes y familiares, la ciencia psiquiátrica en dictadura militar y las reformas sociales del proyecto asilar en tiempos neoliberales. Estos temas pueden ser estudiados, entre otros, en el emergente archivo. La valoración de estos registros no es solo de importancia para la disciplina histórica o las ciencias biomédicas, sino también, para la discusión contemporánea sobre el modelo de salud que necesitamos en un proceso político de demandas sociales. En la cual, la salud mental se encuentra presente en la crítica sobre las carencias del modelo neoliberal. El archivo del HPEP es una evidencia de aciertos y errores, en una sociedad contemporánea, donde el sufrimiento psíquico se ha naturalizado y administrado a partir de los intereses económicos de una sociedad de mercado. Un pequeño aporte al debate, en el cual las experiencias clínicas e históricas de "los abandonados" son vestigios y claves para volver a formular una relación más democrática entre ciencia y sociedad.

El HPEP acogió desde fines de la década de 1940 al Instituto de Reeducación Mental, creado por ley de la República como política pública para enfrentar el alcoholismo como un asunto médico. La construcción del Instituto, las terapias que implementó y los cambios que sufrió en el tiempo, hasta su abandono, permiten acercarse al tipo de políticas públicas que se han elaborado en Chile sobre salud mental. A través de las historias clínicas es posible evidenciar la judicialización del alcoholismo y el carácter científico-médico con el que se asume su asistencia, al mismo tiempo que permite intentar posibles evaluaciones de la misma. Este es un tema absolutamente vigente en los debates actuales de la sociedad chilena.

El desarrollo actual de la historiografía chilena en torno a las políticas públicas de salud ha cuestionado el concepto exclusivamente institucional que operó durante gran parte del siglo XX respecto de ese tópico. Desde hace un tiempo, y dada especialmente la naturaleza de la salud mental, vienen 
estudiándose las propuestas de diversos actores sociales que participan en la reflexión e implementación de acciones de salud que apuntan al mejoramiento de la salud comunitaria. En el caso chileno, además, las políticas privatizadoras de la salud de la Dictadura Militar profundizaron el histórico abandono de la asistencia mental. En ese contexto surgieron, principalmente en la Facultad de Medicina Sur de la Universidad de Chile, iniciativas de rehabilitación de pacientes crónicos internados en el HPEP. Una de ellas fue implementada entre 1976 y 1978, con base en la psicología conductual, pero inserta en una propuesta de salud mental comunitaria, con la intención de mantener vigente de alguna manera las propuestas que desde esa misma área sur se habían implementado exitosamente entre 1968 y 1973. Esta es una de las líneas de investigación que estamos desarrollando actualmente a partir del trabajo realizado en el archivo. Otra iniciativa de índole similar fue llevada a cabo por la Dirección de la Dra. Mary Hamuy Berr entre 1969 y 1972, en la ciudad de Viña del Mar, concretamente en Quebrada Verde, donde se compraron departamentos para que algunos pacientes del HPEP se trasladaran a vivir allí. Estos hogares protegidos se organizaron como una comunidad supervisada por algunos funcionarios que fueron capacitados para esa labor. Entre las entrevistas que hemos realizado para la implementación del Archivo se encuentran relatos de esta experiencia. Ambas iniciativas, en distintos contextos históricos y políticos, operaron como ensayos de posibles futuras políticas de salud extendidas a otros grupos.

El HPEP es el gestor de uno de los hitos más vistosos del proceso de reforma psiquiátrica en Chile. En el año 2002, en el marco del proceso de cambios de la salud mental en Chile, el Pabellón 7, símbolo del modelo asilar deslegitimado en el mundo occidental desde fines del siglo XIX, fue clausurado simbólicamente en presencia de la Comisión Nacional de Derechos Humanos. Las fotografías del pabellón permiten visualizar sus características carcelarias más que terapéuticas. Nosotros levantamos también información, tomando nuevas fotografías del recinto ya que durante estos dos años ha sufrido numerosos incendios y se encuentra en riesgo constante de destrucción. Actualmente se encuentra completamente siniestrado, a pesar de guardar aún valiosa documentación sobre los funcionarios e historias clínicas de los pacientes. Por último, permite el análisis de otros factores, en general poco estudiados, que inciden poderosamente en el éxito o fracaso de las políticas de asistencia mental, especialmente lo vinculado a los determinantes sociales de salud y al papel que juegan otros estamentos institucionales, como los funcionarios. 
En diálogo con las reflexiones historiográficas y políticas previas, la antropología social ha estudiado recientemente los archivos como "campos de fuerza" que agitan energías políticas (Stoler 22). Más que testigos silentes de un pasado por descubrir, ellos representan memorias colectivas por construir que nos permiten iluminar violencias epistémicas y físicas sobre cuerpos y sujetos marginalizados. De acuerdo con Ketelaar, los archivos fueron considerados templos para la conservación del poder, pero en la actualidad son considerados instrumentos de defensa de la ciudadanía. En un sentido similar, Itxaso Martin reflexiona sobre la capacidad del archivo psiquiátrico para generar agencia desde el propio proceso de investigación, en este caso, una monografía sobre un grupo de mujeres ingresadas en un manicomio del País Vasco durante el franquismo.

La investigación documental e historiográfica en curso nos permite ir más allá del patrimonio hospitalario para dar cuenta de una trama compleja de actores que resitúan a la antigua colonia-hospital en la trama política de la ciudad. A modo de ejemplo, la Furia de los caballos sin patas ilustra muchos de los puntos ciegos que aún se mantienen en el proceso de reconversión asilar. La caja de pandora se está abriendo y es hora de aguzar la mirada. 


\section{REFERENCIAS BIBLIOGRÁFICAS}

\section{Documentos}

Boisier, Iris, y Mercedes Fariña. Diagnóstico de Hospitales Psiquiátricos Chilenos, 1997. Sub-Fondo Dirección, Archivo HPEP.

Martínez, Margarita. Historia del Hospital Psiquiátrico El Peral, 1997. SubFondo Dirección, Archivo HPEP.

Zanghellini, Germán. Antecedentes Históricos, 1977. Sub-Fondo Dirección, Archivo HPEP.

\section{BIBLIOGRAFÍA}

Anz, Thomas. "Argumentos médicos e historias clínicas para la legitimación e institución de normas sociales". Literatura, cultura, enfermedad, compiladores Wolfgang Bongers y Tanja Olbrich, Paidós, 2006, pp. 2945.

Araya, Claudia. "Mujeres, médicos y enfermedad mental en la segunda mitad del siglo XIX". Historia de las mujeres en Chile. Tomo 1, editores Ana María Stuven y Joaquín Fermandois, Taurus, 2010, pp. 427-454. https:// doi.org/10.15517/es.v79i2.40162

Armijo, María Alejandra. Psiquiatría en Chile. Apuntes para una historia. Royal Pharma, 2010.

Basaglia, Franco, y Franca Basaglia Ongaro. Morire di classe: La condizione manicomiale, fotografata da Carla Cerati e Gianni Berengo Gardin. Einaudi, 1969.

Bell, Paula. Locura y familia: sesenta casos del manicomio nacional entre 1925-1950. Tesis Licenciatura, Pontificia Universidad Católica de Chile, Santiago, 1995. Impreso.

Camus, Pablo. Filantropía, medicina y locura: la Casa de Orates de Santiago: 1852-1931. Tesis Licenciatura, Pontificia Universidad Católica de Chile, Santiago, 1993. Impreso. https://doi.org/10.7764/psykhe.28.4.1707

Carrillo, Claudia, y Pamela Figueroa. "La locura en el Chile decimonónico". Dimensión Histórica de Chile, vol. 10, 1995, pp. 187-192

Cook, Terry. "Evidence, memory, identity, and community: four shifting archival paradigms". Archival science, vol. 13, no. 2-3, 2013, pp. 95-120. https:// doi.org/10.1007/s10502-012-9180-7

Correa, María José. "De la Casa de Orates al Open Door: el paisaje en el proyecto asilar chileno, 1852-1928". Asclepio, vol. 69, no. 2, 2017. p. 192. https:// doi.org/10.3989/asclepio.2017.15 
Cruz-Coke, Ricardo. Historia de la Medicina Chilena. Editorial Andrés Bello, 1995. Di Petta, Gilberto. Il manicomio dimenticato. Immagini di esistenze sepolte tra le rovine della follia. Edizioni Univ. Romane, 1994.

Didi-Huberman, Georges. La invención de la histeria. Charcot y la iconografía fotográfica de la Salpêtrière. Cátedra, 2007.

Escobar, Enrique, et al., editores. De Casa de Orates a Instituto Psiquiátrico: 150 años de historia. Sociedad Chilena de Salud Mental, 2002.

Gallois, William. "Ethics and Historical Research". Research Methods in History, editores Simon Gunn y Lucie Fairlie, Edinburgh University Press, 2011, pp. 201-219.

Goffman, Erving. Internados. Amorrortu editores, 2012.

Golcman, Alejandra. "Introducción: escenarios de las prácticas psiquiátricas en América Latina (siglos XIX y XX)". Asclepio, vol. 69, no. 2, 2017, p. 188. https://doi.org/10.3989/asclepio.2017.08

---. El trabajo clínico psiquiátrico en el Buenos Aires del siglo XX. Catarata, 2017.

Gómez, Mauricio, y Mario Villanueva. "Hospital Psiquiátrico El Peral". Psiquiatría en Chile. Apuntes para una historia, editora María Armijo, Royal Pharma, 2010, pp. 30-47.

Grigoriadou, Eirini. "La fotografía y la escritura documental del archivo institucional". Escritura e imagen, vol. 10, 2014, pp. 77-96. https://doi. org/10.5209/rev_esim.2014.v10.46402

Heredia, Antonia. ¿Qué es un archivo? Ediciones Trea, 2007.

Huertas, Rafael. "Las historias clínicas como fuente para la historia de la psiquiatría: posibles acercamientos metodológicos". Frenia, vol. I, Fasc. 2, 2001, pp. 7-33.

---. Historia cultural de la psiquiatría. Los Libros de la Catarata, 2012.

---. "Imágenes de la locura: El papel de la fotografía en la clínica psiquiátrica". Maneras de mirar. Lecturas antropológicas de la fotografia, editores Carmen Ortiz García, Antonio Cea Gutiérrez, y Cristina Sánchez Carretero, Consejo Superior de Investigaciones Científicas, 2005, pp. 109-122. https://doi.org/10.3989/ris.2007.07.13

Ketelaar, Eric. "Archival temples, archival prisons: Modes of power and protection". Archival Science, vol. 2, no. 3-4, 2002, pp. 221-238. https:// doi.org/10.1007/bf02435623

Klein, Alexandre, Isabelle Perreault y Marie-Claude Thifault. "Présentation: L'archive psychiatrique”. Santé Mentale au Québec, vol. 41, no. 2, 2016, pp. 9-19. https://doi.org/10.7202/1037951ar 
Klein, Alexandre. 'Des fonds à préserver. L'engagement de l'historien.ne pour la sauvegarde du patrimoine archivistique”. Histoire engagée, 11 Octubre de 2018. http://histoireengagee.ca/des-fonds-a-preserver-lengagementde-lhistorien-ne-pour-la-sauvegarde-du-patrimoine-archivistique/

Laín Entralgo, Pedro. La historia clínica. Historia y teoría del relato patográfico, Consejo Superior de Investigaciones Científicas, 1950.

Lavín, Angélica, editora. Cartas desde la Casa de Orates. Dirección de Bibliotecas, Archivos y Museos, 2003.

LeBel, Marie. "Manque de collaboration, manque d'effectifs ou disparition des données: le nécessaire et difficile accès aux archives psychiatriques". Santé Mentale au Québec, vol. 41, no. 2, 2016, pp. 41-49. https://doi. org/10.7202/1037954ar

Leyton, César. "La ciudad de los locos: industrialización, psiquiatría y cuestión social. Chile 1870-1940". Frenia vol. 8, no. 1, 2004, pp. 259-275.

Linares, Juan Luis. La historia clínica en el manicomio: el pasaporte de la locura, Anagrama, 1976.

Marconi, Juan. Del Asilo a la comunidad. 50 años de psiquiatría chilena 19481998. Un testimonio personal. Memorias inéditas, 1998.

Martínez Azumendi, Oscar, y Luisa Serrulla Vangeneberg. "Siglo y medio de psiquiatría a través de la fotografía italiana". Frenia, vol. 8, no. 1, 2008, pp.183-206.

Molettieri, Camila. Una nueva perspectiva en el tratamiento de las enfermedades mentales: ficha clínica y terapias biológicas en el Hospital Psiquiátrico de Santiago (1936-1951). Tesis de Licenciatura, Universidad Alberto Hurtado, Santiago, 2011. Impreso. https://doi. org $/ 10.2307 / \mathrm{j} . \operatorname{ctvm} 7 \mathrm{bdr} 7.30$

Neuschwander, Isabelle. "Pour quelle raison les instruments de recherche de la série X sont-ils peu nombreux?". Gazette des archives, vol. 167, no. 1, 1994, pp. 347-353. https://doi.org/10.3406/gazar.1994.3328

Ríos, Andrés. "Locos letrados frente a la psiquiatría mexicana a inicios del siglo XX". Frenia vol. 4, no. 2, 2004, pp. 17-35.

Ríos, Andrés, et al. "Los pacientes del Manicomio La Castañeda y sus diagnósticos. Una propuesta desde la historia cuantitativa (México, 19101968)". Asclepio, vol. 68, no. 1, 2016, p. 136. https://doi.org/10.3989/ asclepio.2016.15

Rivera Garza, Cristina. La Castañeda: Narrativas dolientes desde el Manicomio General, México, 1910-1930. Tusquets, 2012.

Roa, Armando. Demonio y psiquiatría. Aparición de la conciencia científica en Chile. Andrés Bello, 1974. 
Santos, Paulo Roberto Elian dos, y José Mauro da Conceição Pinto. "Arquivos de instituições de saúde: história e políticas públicas". Arquivo \& Administração, vol. 9, no.1, 2010, pp. 25-36.

Schultz, Franciso. La furia de los caballos sin patas. Film, 2001.

Scull, Andrew. Museums of Madness: The Social Organization of Insanity in Nineteenth-Century England. Allen Lane, 1979. https://doi.org/10.1017/ s0018246x00008165

Stoler, Anne Laura. Along the archival grain: Epistemic anxieties and colonial common sense. Princeton University Press, 2010. https://doi.org/10.1017/ s0395264900015584

Venancio, Ana Teresa, y Gisélia Potengy, organizadoras. $O$ asilo e a cidade. Histórias da Colônia Juliano Moreira. Garamond, 2015.

Villasante, Olga, et al. Cartas desde el manicomio: experiencias de internamiento en la Casa de Santa Isabel de Leganés. Los Libros de la Catarata, 2018.

Wright, David, y Renée Saucier. "Madness in the Archives: Anonymity, Ethics, and Mental Health History Research". Journal of the Canadian Historical Association, vol. 23, no. 2, 2012, pp. 65-90. https://doi. org/10.7202/1015789ar 